\title{
EDITORIAL
}

\section{Freddie Fu: A Leader of Leaders}

\author{
Nicholas P. Drain ${ }^{1}$ (D) Christopher D. Murawski ${ }^{1}$ - Benjamin B. Rothrauff ${ }^{1} \cdot$ Stephanie A. Boden $^{1}$. \\ Nyaluma N. Wagala ${ }^{1} \cdot$ Emily A. Whicker $^{1} \cdot$ Bryson P. Lesniak ${ }^{1} \cdot$ Volker Musahl $^{1}$
}

Received: 15 November 2021 / Accepted: 23 November 2021 / Published online: 5 January 2022

(c) The Author(s) under exclusive licence to European Society of Sports Traumatology, Knee Surgery, Arthroscopy (ESSKA) 2021

\begin{abstract}
Freddie Fu had a profound and undeniable impact on the field of orthopaedic surgery. He was a leader both personally and professionally and dedicated his career to ensuring that those around him had the opportunity to thrive. His life and career were distinguished by his exceptional leadership, boundless collaboration, and dedication to diversity. Freddie Fu's ability to train future leaders represents one of his greatest professional legacies, which will continue to permeate the field of orthopaedic surgery for decades to come. He was a giant, and those fortunate enough to train under him are better because of it.
\end{abstract}

Freddie Fu was a giant, both locally in Pittsburgh and throughout the world. Whilst it is impossible to adequately describe his unique personality or personal and professional impacts in any brief way, one of his most notable and undeniable qualities was that he was a natural and fearless leader. Freddie was a leader of leaders, and lifted others up with him as he rose in stature. In addition to his leadership, he was a trailblazer-in orthopaedics, sports medicine, and in life. Whether it was introducing sports medicine to the city of Pittsburgh, defining the modern principles for anatomic anterior cruciate ligament (ACL) reconstruction, or his steadfast commitment to integrating women and minorities into the field of orthopaedic surgery-decades before it became part of the broader spotlight- - he always thought critically, challenged the norm, and lived by the saying of "do the right thing." He was not just a leader or trailblazer on paper, but he actually "walked the walk" and led by example.

Freddie brought out the best in those around him and consistently raised the standards for his colleagues and trainees. Whether you worked with him for five minutes or many years, he instilled the importance of working for something larger than oneself. It did not matter to him what your background was or what title you held; he treated everyone with respect and compassion and had an uncanny way of making everyone feel included and important. He demonstrated

Nicholas P. Drain

nick.drain25@gmail.com

1 Department of Orthopaedic Surgery, UPMC Freddie Fu Sports Medicine Center, University of Pittsburgh Medical Center, Pittsburgh, PA, USA what it meant to be a great leader. As a result, he raised the standards for his thousands of patients, ranging from elite Olympic and professional athletes from around the globe to regular 'Pittsburghers' from around the corner. His genuine warmth, charisma, and sincere interest in everyone he knew-colleagues, patients, and everyone in between, combined with his unrelenting work ethic and collaborative research efforts, set the stage for transforming orthopaedic surgery at Pitt, UPMC, and sports medicine worldwide.

After immigrating from Hong Kong, Freddie eventually made Pittsburgh his home. He earned his medical degree at the University of Pittsburgh (Pitt) School of Medicine in 1977 and completed his residency at Pitt as well. He subsequently became faculty in 1982 and went on to become Pitt's David Silver Professor and Chairman of the Department of Orthopaedic Surgery in 1998, a position he held until his passing. In 2010, he was bestowed with one of Pitt's highest honors as a Distinguished Service Professor.

Prior to becoming chairman of orthopaedic surgery at UPMC, Freddie founded western Pennsylvania's first orthopaedic sports medicine program in 1986. The program quickly outgrew its initial location in a small suite as more and more trainees sought sports medicine fellowship positions. In 2000, UPMC Sports Medicine was moved to a newly built state-of-the-art facility located on the South Side of Pittsburgh. Named the UPMC Rooney Sports Medicine Complex, the facility was envisioned and designed by Freddie and was the first of its kind in combining resources from a major academic health system with those from professional (National Football League's Pittsburgh Steelers) and collegiate (University of Pittsburgh Panthers) sports programs. 
The success of the sports complex led to UPMC opening a second complex in collaboration with the National Hockey League's Pittsburgh Penguins, named the UPMC Lemieux Sports Complex. Freddie Fu's original vision set a standard for numerous sports medicine complexes worldwide. In 2018, the sports complex in the South Side of Pittsburgh was, quite appropriately, renamed the UPMC Freddie Fu Sports Medicine Center in his honor.

The growth of the Sports Medicine in the Department of Orthopaedic Surgery under Freddie's leadership paralleled that of UPMC's orthopaedic surgery residency program. The residency program continues to be one of the most ethnically and gender-diverse academic programs in the country. Freddie not only emphasized and supported diversity amongst the residency program, but practiced a lifelong commitment to inclusion, diversity, and equity throughout the field of orthopaedic surgery. For his persistent mentorship and support of diversity, he received the 2011 American Academy of Orthopaedic Surgeons Diversity Award. After his passing, the Ruth Jackson Orthopaedic Society (RJOS), a society dedicated to increasing diversity in the field of orthopaedics, named an award in his honor- the "Freddie Fu He For She Award" to honor his legacy and commitment to inclusion. Freddie Fu's inclusive mindset and collaborative spirit transcended modern boundaries and he welcomed residents, fellows, and international research fellows from around the globe to train with and learn from the best in orthopaedic surgery.

Whilst his accomplishments are innumerable, Freddie's greatest professional and enduring legacy will be the people he trained and the opportunities that he provided. Throughout his nearly 40-year career at UPMC, he helped train over 300 residents, 130 clinical fellows, and 700 international fellows from 62 different countries. Remarkably, over 25 of his trainees have been appointed department chairs throughout the world and over 50 more have been appointed chiefs within their respective divisions. Undoubtedly, this list will continue to expand in the years to come. Regarding research, Freddie's extensive work included 148 individual co-authors who published more than five papers with him and over 150 trainees achieving an h-index of 10 or higher.

At times, Freddie seemed like a force of nature. He made things possible that seemed impossible. He broke down barriers and equipped those around him with values and principles to succeed both personally and professionally. $\mathrm{He}$ also had an uncanny ability to motivate everyone around him. "You have to be better than me," he would say, as if to impart what seemed to be an insurmountable challenge upon his trainees. Above all, he was one-of-a-kind. Whilst it will never be quite the same without him, his impact on the field of orthopaedic surgery was so great that it will transcend time. Undoubtedly, Freddie's name will stand amongst the likes of fellow famous Pittsburghers as enduring giants, including Andrew Carnegie, ${ }^{1}$ Andy Warhol, ${ }^{2}$ Rachel Carson, ${ }^{3}$ Fred Rogers, ${ }^{4}$ Dan Rooney, ${ }^{5}$ Dr. Jonas

\footnotetext{
1 Andrew Carnegie (November 25, 1835-August 11, 1919) was an industrialist and philanthropist who led the expansion of the American steel industry in the late nineteenth century. He built Pittsburgh's Carnegie Steel Company, which he sold to J.P. Morgan in 1901 for $\$ 303,450,000$; it formed the basis of the U.S. Steel Corporation. During the last 18 years of his life, Carnegie gave away around $\$ 350$ million (approximately $\$ 5.2$ billion in 2020), almost 90 percent of his fortune, to charities, foundations, and universities. His 1889 article proclaiming "The Gospel of Wealth" called on the rich to use their wealth to improve society. In 1885 , he gave $\$ 500,000$ to Pittsburgh for a public library and in 1886 , he gave $\$ 250,000$ to Pittsburgh's Allegheny County for a music hall and library.

2 Andy Warhol (August 6, 1928-February 22, 1987) born and raised in Pittsburgh, PA, was an American artist, film director, and producer who was a leading figure in the visual art movement known as pop art. His works explore the relationship between artistic expression, advertising, and celebrity culture that flourished by the 1960 s. Some of his best-known works include the silkscreen paintings: Campbell's Soup Cans (1962) and Marilyn Diptych (1962), the experimental films Empire (1964) and Chelsea Girls (1966), and the multimedia events known as the Exploding Plastic Inevitable (1966-67).

${ }^{3}$ Rachel Louise Carson (May 27, 1907-April 14, 1964) was an American marine, author, and conservationist whose influential book Silent spring (1962) and other writings are credited with advancing the global environmental movement. The book Silent spring spurred a reversal in national pesticide policy, which led to a nationwide ban on DDT and led to the creation of the U.S. Environmental Protection Agency. Carson was posthumously awarded the Presidential Medal of Freedom by President Jimmy Carter.

${ }^{4}$ Fred McFeely Rogers (March 20, 1928-February 27, 2003), also known as Mister Rogers, was born in Latrobe, Pennsylvania near Pittsburgh. He was an American television host, author, producer, and Presbyterian minister. He was the creator, showrunner, and host of the preschool television series Mister Rogers' Neighborhood, which ran from 1968 to 2001.

5 Daniel Milton Rooney (July 20, 1932-April 13, 2017) was an American executive and diplomat best known for his association with the Pittsburgh Steelers, an American Football team in the National Football League (NFL) and son of the Steelers' founder, Art Rooney. The Steelers were very successful during his tenure at president, owner, and chairman, winning 15 division championships, 8 AFC Championships, and an NFL record 6 Super Bowl Championships. He was also credited with spearheading a requirement that NFL teams with head coach and general manager vacancies interview at least one minority candidate, which has become known as the "Rooney Rule." He was elected to the Pro Football Hall of Fame in 2000.
} 
Salk ${ }^{6}$ Dr. Thomas Starzl ${ }^{7}$ and Dr. Henry Mankin. ${ }^{8}$ We are all better because of Freddie Fu.

$\overline{6}$ Jonas Edward Salk (October 28, 1914-June 23, 1995) was an American virologist and medical researcher. In 1947, Salk became a professor in the School of Medicine at the University of Pittsburgh, where he later developed one of the first successful polio vaccines. Less than 25 years after the release of Salk's vaccine, domestic transmission of polio had been eliminated in the United States.

7 Thomas Earl Starzl (March 11, 1926-March 4, 2017) was an American physician, researcher, and expert on organ transplants. He performed the first human liver transplants and has often been referred to as "the father of modern transplantation". He also made immense contributions to the field of immunosuppression. In 1996, the Pittsburgh Transplantation Institute was renamed by UPMC as the Thomas E. Starzl Transplantation Institute. In 2006, the University of Pittsburgh renamed one of its newest medical research buildings the Thomas E. Starzl Biomedical Science Tower.

${ }^{8}$ Henry J. Mankin, M.D. (October 9, 1928-December 22, 2018) was a Pittsburgh Native, earning both his undergraduate and medical education at the University of Pittsburgh. He went on to become the Edith M. Ashley Professor of Orthopaedics Emeritus at Harvard Medical School and Chair of the Department of Orthopaedic Surgery at Massachusetts General Hospital. Mankin was a pioneer in the field of musculoskeletal oncology. His pioneering research on cartilage and focus on education in Orthopaedic Surgery only begin to highlight the tremendous impact he has had in Orthopaedics.

\section{Declarations}

Conflict of interest The authors have no conflicts of interest to disclose.

Publisher's Note Springer Nature remains neutral with regard to jurisdictional claims in published maps and institutional affiliations. 